\title{
AYURLOG
}

National Journal of Research in Ayurved Science

http://www.ayurlog.com $\quad J u l y-2020 \mid$ Volume $08^{\text {th }} \mid$ Issue: $4^{\text {th }}$

ISSN: $2320-7329$

\section{"To study the efficacy of yoga in maintaining health and its effects on various systems of human body."}

\author{
Rohini Kawale ${ }^{1}$ U. K. Bande ${ }^{2}$ \\ P.G. Scholar ${ }^{1}$, HOD \& Guide ${ }^{2}$
}

Sharirakriya Department, Yashwant Ayurvedic Medical and Research Center,

Kodoli, Panhala, Kolhapur, Maharashtra - 416114

*Corresponding author: E-mail : rohinikawaler@ gmail.com Mob. +91 9769731924

\section{ABSTRACT :}

AIM: To study the effects of yoga on various systems of Human Body. The objective of this study is to provide a comprehensive review of benefits of regular Yoga practice on various system of body. DISCUSSION AND CONCLUSION: It is important for health care professionals to be informed about nature of Yoga and evidence of its many therapeutic effects. Yoga has been practiced in India since time immemorial. In ancient Indian medicinal system, Yoga practice is described as the link between an individual and universe. It is considered to be means for physical, mental and spiritual growth of an entity. With increasing research evidence. OBSERVATION: Yoga has been emerging as a powerful tool to achieve good state of health both at physical and mental levels. Yoga includes physical postures, regulated breathing (Pranayam), Meditation (Dhyan) and relaxation which is helpful in improving lifestyle and also in bringing down prevalence of medical emergencies like psychological, neurological and metabolic disorders. Moreover it helps people to remain happy and healthy even in stressful conditions. RESULTS: Results show that Yoga enhance strength and flexibility, promote and improve respiratory and cardiovascular function, improve digestive system, reproductive system, improve immunity, improve Sleep patterns, reduce stress, anxiety depression and enhance overall well-being and quality of life.

KEYWORDS: Yoga, Physical health, Mental Health, therapeutic effect, lifestyle, stress, anxiety, flexibility, quality life.

\section{INTRODUCTION:}

According to WHO, Health is a state of physical, mental and social well-being in which disease and infirmity are absent.(1) Since WHO officially began promoting Yoga in developing countries in 1978, Yoga has been rated for its therapeutic potential.

Yoga derives from Sanskrit word yuj meaning to bring, join, attach and yoke, to direct and concentrate one's attention on, to use and apply. It also means union or communion.(2) Yoga has collated, coordinated and systematized by Patanjali in his classical work Yoga Sutras, which consists of 185 terse aphorisms.(2) $\mathrm{He}$ advocated 'Ashtanga Yoga' for an all round development of human personality. Yoga philosophy classified into 4 streams -

\section{Karma Yoga :}

Path of work, promotes, pleasure in labour without indulging in thoughts of success or failure.

\section{Bhakti Yoga :}


Path of worship - systematic method of engaging mind in practice of divine love. This attitude softens our emotions and tranquilizers our mind.

\section{Gyana Yoga :}

Path of philosophy, a systematic way of enlightening the mind about realities of life by contemplation.

\section{Raja Yoga :}

Path of psychic control, a systematic process of culturing mind.

Hatha Yoga and Raja Yoga complement each other and form a single approach towords liberation.(3)

Yoga is a science as well as an art of healthy living. The physical exercise (Asanas) may increase physical flexibility co-ordination and strength while breathing practices (Pranayam) and meditation (Dhyan) may calm and focus the mind to develop greater awareness and diminish anxiety.4) Sustain practice also leads to important outcomes such as changes in life perspective, selfawareness and an improved sense of energy to live life fully and with genuine enjoyment.(5)

\section{AIM AND OBJECTIVES:}

1) To study functions of various human body systems.

2) To study the effect of yoga on various body systems.

\section{MATERIALS AND METHODS:}

1) Ayurvedic literature.

2) Modern books.

3) Magazines, research articles, Pubmed, Medline etc.

\section{OBSERVATION :}

Effects of Yoga on various human body systems :

\section{Cardiovascular System :}

It is an organ system conceding of heart and blood vessels that permit blood to circulate and transport nutrients, oxygen, carbon dioxide, hormones and blood cells to and from the cell in body to provide nourishment, stabilize temperature and $\mathrm{pH}$ and maintain homoeostasis.

-Yoga increase blood flow and levels of hemoglobin and red blood cells which allows for more oxygen to reach the body cells, enhancing their function.(6)

-It also thins the blood which can decrease the risk of heart attack and stroke, as they are of often caused by blood clots.

-Many studies show Yoga lowers the resting heart rate and increase endurance and can improve the maximum uptake and utilization of oxygen during exercise. $(7,8,9)$

-Yoga practices shown to improve cardiorespiratory performances, psychological prolife and plasma melatonin levels and also significantly reduced systolic $\mathrm{BP}$ diastolic BP, mean arterial pressure and orthostatic tolerance.(9)

-Yoga based lifestyle modifications were also shown to aid in regression of coronary lesions as well as to improve myocardial perfusion inpatients with CAD.(10)

Some of the important Aasanas for heart health are Tadasa, Vrikshasana, Uttita Hastapadasana, Trikonasan, Veerabhadrasana, Utkatasan, Marjariasana, Adhomukho Shwanasanas, Bhujangasana, Dhanurasana, Setu Bandhasana, Shalambha Sarvangasana, Ardha Matsyendrasana, Paschimottasana, Dandasan, Ardha Picha Mayurasana, Makaraadhomukha Shwanasana, Shavasana Anjali Mudra.

\section{Respiratory System :}

It is the organs and other parts of body involved in breathing, when you exchange oxygen and carbon dioxide. It includes nose 
and nasal cavity sinuses, mouth, pharynx, larynx, trachea, diaphragm, lungs, bronchial tubes, bronchioles, alveoli and capillaries.

-Improvement of various parameters of lung function reported in healthy volunteers practicing Yoga. Patients with asthma described improvement in peak expiratory flow rate, medication use and asthma attack frequency.(11)

- It is found that Yoga has been beneficial in patients having COPD. Yoga improves diffusion capacity.(12)

-Yogasana involves an isometric contraction which help to increase the skeletal muscle strength or improves the strength of inspiratory and expiratory muscle.(13)

Some of the important Yogasanas and breathing techniques useful in respiratory system -

\section{Kapalbhati :}

Helps in removal of secretions from bronchial tree and helps in clearing respiratory passages.(12)

\section{Nadi Shodhan Pranayam -}

Respiratory apparatus gets emptied and filled more completely and efficiently. This stretches elastin and collagen fibers of lung parenchyma and lungs inflated near to total lungs capacity. This is a major physiological stimulus for release of lung surfactant into alveolar spaces which increase lung compliance.(14)

Purna Ushtra Asana, Sampurna Matsya Asana, Sarwangasana, Bala Asan, Sharabha Asana, Kukkriya Pranayam are helpful in breathing disorders.

\section{Musculoskeletal System -}

This system consists of bones, muscles and joints. It is designed for support locomotion and protection of internal organs.

-Numerous studies show that Asana, meditation or a combination of the two can reduce pain and disability while improving flexibility and functional mobility in people with a numbers of conditions causing chronic pain. $(5,6,15,16)$ In some cases use of pain medication was reduced or eliminated completely.

-Yoga also shown to improve gait function and reduce age related changes in gait among group of healthy, non-obese elders.(17)

-Yoga helps to build muscle mass or maintain muscle strength which protects from condition such as arthritis, osteoporosis and back pain.(5)

-Some of the Yogasana which tones muscles, increase strength and flexibility, remove stiffness and pain.

Trikoasan, Virbhadrasan, Parsvotanasan, Ushtrasan, Dhanurasan, Shalabhasana, Chaturanga, Dandasana, Bhujangasana, Shwanasana, Parchimottanasan, Purvottanasana, Supta Konasana, Padangushtasana.

\section{Digestive System:}

It is a series of hollow organs joined in a long twisting tube from mouth to anus. Inside the tube, there is mucus lining which helps for digestion by producing digestives juices. Intake of food, digestion, absorption and assimilation of food, water balance, elimination of wastes are functions of this systems.(18)

-The complete elimination of waste product from the body is promoted by Yogasana which not only massage and activate internal muscles for peristaltic activity but also keep internal organ in their proper place in the abdominal cavity; preventing prolapse of stomach, intestine.(19)

-Yoga increase digestive power, decrease bloating sensation in abdomen, relieves gastric troubles, relives constipation. 
-Some of the Yoganasans are as follows :

Padothanasana,

Padangushtasan,

Uttanasana, Shalbhasana, Navasana,

Pachimottanasana,

Sarvangasana,

Jatharparivartanasana,

Mayursana,

Janushirshasana,

Yogamudrasana,

Suryabhedana, Shitalipranayam etc.

\section{Reproductive System :}

It is a system of sex organs within body which work together for purpose of sexual reproduction. Major female reproductive organs are the Vagina, uterus ,fallopian tubes and ovaries. Male reproductive system include penis, scrotum, testis, epididymis, vas deferens, prostate and seminal vesicles.

-During puberty Yoga assist in balancing out the mood swings and eliminating the body aches resulting from hormonal imbalance experienced during sexual maturing.

-Moola Bandha stretches muscles of pelvic floor increase circulation in that area, balance, stimulates and rejuvenates the area. So, exercise that utilize Moola Bandha may be helpful in aiding people who lack sexual vitality and have poor sexual functioning.

-Some studies reported role of Kundalini Yoga in regulation of terminal prostate cancer.(20)

-Study reports that Yoga poses reduce severity and duration of primary dysmenorrhea.(21)

-Studies in India have shown positive impacts of Yoga exercise on women with PMS on decreasing heart beats, blood pressure and anxiety. Yoga reduces harmful inflammatory secretions which make women with PMS comfortable.(22)

-Even 8 weeks of an integrated approach to Yoga therapy resulted in better outcome as compared to physical activity in reducing climacteric symptoms, perceived stress and neuroticism in premenopausal women.(23)

-Some of the Yogasanas that regularizes menstrual cycle, boost fertility, decrease menstrual disorders are Uttanasana, Sarvangaasana, Halasana, Supta Baddha Konasana, Upavishta Konasana, Viparita Karani, Bhujangasana, Setu Bandhasana.

-Kapalabhati can be useful in PCOS.

\section{Endocrine System :}

It is the collection of glands that produce hormones that regulate metabolism, growth and development, tissue function, sexual function, reproduction, sleep and mood.

-Yoga is an alternative therapy for diabetes with not only physical but also psychological benefits. It improves blood glucose, lipid profiles and oxidative stress.(24)

-Some of the Yogasana that squeezes and compress the abdomen and helps stimulate the pancreatic secretions or hormonal secretions :

Ardha Matsyendrasana combined with Dhanurasana, Vakrasana, Halasana.

-Yoga poses pressurize and depressurize specific glands and there subtle compression and decompression can regulate secretions. It may have beneficial effect on our stress response. Yoga Nidra is great way to control stress and emotion.

-The practice of Yoga produces a physiological state opposite to that of flight or fight stress response and with that interruption in stress response, a sense of balance and union between body and mind can be achieved.(25)

-Yogasana like Setu Bandhaasana and Bhujangasana stimulate testis and ovaries.

Halasana, Matsyasana improve functioning of thyroid and parathyroid gland. Urdhva 
Dandasana, helps proper blood supply to pituitary and pineal gland.

\section{Nervous Systems :}

It is a complete network of nerves and cells that carry message to and from the brain and spinal cord to various parts of body.

-Yoga practices inhibit the areas responsible for fear, aggressiveness and rage and stimulate the rewarding pleasure center in the median forebrain and other areas leading to a state of bliss and pleasure. This inhibition result in lower anxiety, HR, RR, BP, cardiac output. $(5,7)$

-Most studies on Yoga offered some evidence that Yoga promotes a reduction in sympathetic activation, enhancement of cardio vagal functions and shift in ANS balance from primarily sympathetic to parasympathetic.(26)

-Consistent Yoga practice improves depression and can lead to significant increase in serotonin levels coupled with decrease in levels of monamine oxidase, an enzyme that breaks down neurotransmitter and cortisol.(6)

-Some of the Yogasanas that balance nervous system are Uttanasana, Siddhasana,

Urdhva Dandasana, Supta Baddha Konasana, Setu Bandhasana, Viparit Karni, Balasana, Halasana, Ardha Matsyendrasana, Anulom-Vilom, Adhomukha Svanasana.

\section{Miscellaneous :}

-While Yoga is not a cure for a cancer, nor definitive way of preventing it, Yoga increase physical, emotional and spiritual wellness and brings about a certain peace, of which many cancer patients desire.(26)

-Regular practice of Yoga resulted in a significant decrease in time taken to fall asleep, an increase in total member of hours slept and in the feeling of being rested in the morning.(27)

-Practicing Yoga and meditation as a means to manage and relieve both acute and chronic stress helps individual overcome other comorbidities associated with diseases and leads to increased quality of life.(28)

\section{DISCUSSION :}

Yoga offers an effective method of managing and reducing stress, anxiety, depression and numerous studies demonstrate the efficacy of Yoga on mood related disorders.

Yoga a form of mind body exercise has become an increasingly widespread therapy used to maintain wellness and alleviate a range of health problems and ailments. It should be considered as a complementary therapy in the treatment of stress, anxiety, depression and other mood disorders as it created a greater sense of well-being, increase feelings of relaxation, improves self-confidence and body image, improve efficiency, better interpersonal relationships, increase attentiveness, lower irritability and encourage on optimistic outlook on life. While it is not surprising that physical fitness improved by Yoga or other exercise, it is of interest that in individuals with pain, Yoga may have beneficial effects with overall moderate effect seen strong in healthy persons and weaker in chronic pain conditions. When individual has position mind state healing happens more quickly whereas if mind state is negative, healing may be prolonged. Health care professionals, trainers, educators, need to be aware of potential of Yoga as an important part of a personal wellness plan. Although it may not result in complete elimination of disease from the body but is offers a holistic part of healing. 


\section{CONCLUSION :}

-Yoga has been used to alleviate musculoskeletal pain and has been associated with significant improvement in range of motion and function.

-Yoga helps improve cardiovascular health by lowering blood pressure, cholesterol, heart rate and other risk factors.

-Yoga improves breathing efficiency and decreasing inflammation, keeps respiratory muscles strong and flexible.

-Yoga aids digestion, reduces bloating, tones abdominal organs.

-Yoga reduces stress and anxiety which can improve overall health of reproductive organs.

-Yogasana cause subtle compression and decompression which can regulate hormonal secretions.

-Yoga reduce the activity of SNS and increase the activation of PNS, it strengthens nerves transmission from body to brain decreasing an stress and muscular tension.

\section{REFERENCES :}

1. www.who.ent/who we are. (n.d.).

2. Menuhin, B. I. (2005). The illustrated light on Yoga. Harper Collins Publishers, India, New Delhi.

3. Menuhin, B. I. (2005). The illustated lite on Yoga. Harper Collins Publishers India, New Delhi.

4. Krikward G., Rampan H., Tuffrey, recharson J. etal. Yoga for anxiety A systemic review of research evidence. British Journal of Sports Medicine of 2005; 39(12): 884-891

5. Desikochar K., Brgston L., Bossart C.: Yoga of healing exploring Yogas holistic model for health and well being. Int J Yoga, 2005 ; 15:17-39.
6. Mccall T. New York, Bantam Dell : A division of random house. Inc 2007. Yoga as medicine.

7. Bharashankar J.R. etal. : Effect of Yoga on cardiovascular system in subjects above 40 years. Indian J. physiol pharmacol; 2003; 47:202-6.

8. Briket D.A., Edgren L. : Hatha Yoga improved vital capacity of college students. Altern ther health med. 2000; 6:55-63. (Pub. Med).

9. Harinath K., Malhotra A.S. etol : Effect of Hath Yoga and omkar meditation on cardiorespiratory performance psychological profile and melatonin secretion. J Altern complement Med. 2004; 10:261-8 (Pub-Med)

10. Yogendra J., Ambardekar S. etol. : Beneficial effect of Yoga life style on reversibility of ischemic heart disease caring heart project of international board of Yoga. J Assoc physicians of India. 2004; 52:283-9 (Pub-Med)

11. Roub JA psychophysiology effect of Hath Yoga and musculoskeletal and cardiopulmonary function a literature review. Journal of alternative and complementary medicine : 2002;8(6); 797-812.

12. Holland A.E., Hill CI et.al. : Breathing exercise for COPD a systemic review and meta-analysis. $\mathrm{J}$ thorac Dis. : 2014; 6(6); 795-802.

13. Agnihotri S., Kant S., et.ol. : Impact of Yoga on Biochemical profile of Asthmatics. A randomized control study. Int. Jornal of Yoga : 2014;7:16-22.

14. Iyengar BKS : Light on Yoga; George allan and Unwin ltd. London: 1968; 243-45. 
15. Kolasinki SL Garfinkel $M$ et al .Iyengar ytoga for treating symptoms of osteoarthritis of knees.a pilot study J Altern Complement Med 2005;115;107-17(pub med)

16. William KA. Petronic J et.ol. : Effect of Iyengar therapy for chronic low back pain: 2005;115:107-17(Pub Med)

17. Dr. Beneditto M., Jones KE. Et.ol. : Effect of gentle Iyengar Yoga program on gait in elderly An exploratory. Arch phys med Rehabil : 2005;86:1830-7 (Pub Med)

18. Gore M. M. : Anatomy and physiology of Yogic practices. Kanchana Prakashan - 1991; Pg.7-8.

19. Dalal Nargis : Yoga for rejuvenation. orient longmon ltd. Pg. 16.

20. Shanna Hoff Khalasa DS : Patient perspectives Kundalini Yoga meditation techniques for psychooncology and potential therapies for cancer. Integ cancer ther.: 2005;4:87100 (pub med)

21. Chein L.W., Chag HC, Lie CF : Effect of Yoga on serum homocysteine and nitric oxide levels in adolescent women with and without dysmenorrhea J. Altern complement med: 2013 ; 19-20 (pub med)

22. Michalsen A, Grossmean P, et.al. : Rapid stress reduction and anxiolysis among distressed women as consequence of three month intensive Yoga programming. Med. Sci. Monit 2005

23. Chath R, Raghuram N : Treating climacteric symptoms in Indian women with and integrated approach to Yoga Therapy a randomized control study menopause: 2008; 86270 (pub med)

24. Kalara S, Ayyar V, Unnikrishnan AG : Adrenergic India managing it diabetes Indian J Endocrinol metab: 2011; 15:51-2 (pub med)

25. Arora S, Bhattacharjee J : Modulation of immune response in stress by Yoga.

26. Bavchar S Yoga for cancer. Yoga J 2007. Retrieved form http://yogajournal.com/health

27. Manjunath MK, Teller S, Influence of Yoga and Ayurveda on self rated sleep in a geriatric population Indian J. Med Res. 2005; 121-683-70. (pub med)

28. Oken BS, Zajdal D, Kishiyama S, Flegal K, Dehan C et.al. : Randomized controlled six month trial of Yoga in healthy seniors; effects on cognition and quality of life. Altern ther health med. 2006: (pub med)

"To study the efficacy of yoga in maintaining health and its effects on various systems of human body."

Rohini Kawale, U. K. Bande 